with good AQI according to US-EPA $\left(<12.5 \mu \mathrm{g} \cdot \mathrm{m}^{-3}\right)$ in the car parking area and inside the Bella Center, with a level of $6.0 \pm 1.7$ and $3.0 \pm 0.9 \mu \mathrm{g} \cdot \mathrm{m}^{-3}$, respectively. Peak values were $12.5 \mu \mathrm{g} \cdot \mathrm{m}^{-3}$ and $12.0 \mu \mathrm{g} \cdot \mathrm{m}^{-3}$, respectively. However, outside in front of the Bella Center with smokers, mean PM2.5 was $17.8 \pm 7.5 \mu \mathrm{g} \cdot \mathrm{m}^{-3}$ with a peak of $98.9 \mu \mathrm{g} \cdot \mathrm{m}^{-3}(\mathrm{p}<0.03$, as compared with inside the venue), which is a step down in AQI. PM2.5 along the motorway was only $4.6 \pm 0.7 \mu \mathrm{g} \cdot \mathrm{m}^{-3}$ with a peak value of $8.7 \mu \mathrm{g} \cdot \mathrm{m}^{-3}$. Inside the restaurant, high concentrations of PM2.5 were found $\left(165.1 \pm 8.5 \mu \mathrm{g} \cdot \mathrm{m}^{-3}\right)$ with a peak value of $372.2 \mu \mathrm{g} \cdot \mathrm{m}^{-3}$, with a "very unhealthy" AQI. Official outdoor PM2.5 mean \pm SEM recorded in the town for the time interval of all the measurements was $5.7 \pm 0.4 \mu \mathrm{g} \cdot \mathrm{m}^{-3}$. Overall, mean values observed with smokers in front of the Bella Center and inside the restaurant were significantly higher than the outdoor parking place, indoor Bella Center, motorway and Copenhagen outdoor official data $(p<0.05$ and $p<0.001$, respectively).

Indoor and outdoor air quality monitoring through an entire day showed that in a country where outdoor air quality is generally good, as in Denmark, the presence of ETS worsens both indoor and outdoor PM concentrations. In the restaurant with smokers we observed very high PM2.5 levels, with an AIQ classified as "very unhealthy", as reported by previous studies [7]. PM also reached significant values outdoors where smokers gathered to smoke, confirming previous field surveys at outdoor patios [10]. By appreciating this issue, ERS organisers advised participants not to smoke in front of the Congress venue, a suggestion that also implies coherence with doctor's role model, an issue that still deserves attention.

Understanding the importance of indoor versus outdoor pollution and the issue of environmental tobacco smoke as both an indoor and outdoor pollutant can contribute to a better knowledge of environmental tobacco smoke exposure risk.

\section{ACKNOWLEDGEMENTS}

The authors are grateful to G. Viegi for his helpful discussion.

\section{R. Boffi ${ }^{*}$, A. Ruprecht*, R. Mazza*, M. Ketzel ${ }^{\#}$ and \\ G. Invernizzi*}

*Tobacco Control Unit, National Cancer Institute/SIMG-Italian College of GPs, Milan, Italy, and "National Environmental Research Institute, Roskilde, Denmark.

\section{REFERENCES}

1 Kunzli N. The public health relevance of air pollution abatement. Eur Respir J 2002; 20: 198-209.

2 Viegi G, Simoni M, Scognamiglio A, et al. Indoor air pollution and airway disease. Int J Tuberc Lung Dis 2004; 8: 1401-1415.

3 Repace JL, Lowrey AH. Indoor air pollution, tobacco smoke, and public health. Science 1980; 208: 464-472.

4 Gallus S, Zuccaro P, Colombo P, et al. Effects of new smoking regulations in Italy. Ann Oncol 2006; 17: 346-347.

5 Denmark Law about Smoke-free Environments on Public Premises; means of transportation and the like. Law nr.436 of 06/01/1995. Available online: http://apps.nccd.cdc.gov/ nations/legislation/TextFiles/Denmark_13.htm. Date last accessed: December 2005. Date last updated: November 2005.

6 Smoke Free Europe Conference 2005. http://www.ersnet. org/ers/lr/browse/default.aspx?id_dossier $=31552$. Date last accessed: December 2005. Date last updated: December 2005.

7 Invernizzi G, Ruprecht A, Mazza R, et al. Real-time measurement of indoor particulate matter originating from environmental tobacco smoke: a pilot study. Epidemiol Prev 2002; 26: 2-6.

8 Kemp K, Ellermann T, Palmgren F, Wåhlin P, Berkowicz R. Jørgen Brandt 2005: The Danish Air Quality Monitoring Programme. Annual summary for 2004. National Environmental Research Institute (NERI), Roskilde Denmark. NERI Technical Report No. 544. Link for report: http: $\backslash \backslash$ technical-reports.dmu.dk. Link for recent data: http:// www.dmu.dk/atmosphericenvironment/byer/forside.htm. Date last accessed: December 2005. Date last updated: December 2005.

9 Guideline for reporting of daily air quality-air quality index (AQI). United States Office of Air Quality EPA-454/ R-99-010 Environmental Protection Planning and Standards July 1999.

10 Repace J. Measurements of outdoor air pollution from secondhand smoke on the UMBC campus. http:// www.repace.com/pdf/outdoorair.pdf. Date last accessed: December 2005. Date last updated: November 2005.

DOI: 10.1183/09031936.06.00148505

\title{
COPD: an inhaled corticosteroid-resistant, oral corticosteroid-responsive condition
}

\section{To the Editors:}

Few areas of respiratory medicine have generated as much controversy as the use and purpose of long-term corticosteroid treatment in chronic obstructive pulmonary disease (COPD). However, several recent large, placebo-controlled studies have clarified the role of long-term treatment with inhaled corticosteroids [1-3]. There is now consistent evidence that inhaled corticosteroid treatment, even in high doses, is not associated with a clinically significant reduction in the rate of decline of forced expiratory volume in one second (FEV1). Treatment is associated with a modest reduction in the 
frequency of more severe exacerbations, particularly in patients with more severe disease $[1,4]$ and in those who have a good bronchodilator response to short-term treatment with oral prednisolone $[5,6]$.

The limited effects seen with inhaled corticosteroids is surprising, given that induced sputum evidence of corticosteroid-responsive eosinophilic airway inflammation is present in up to $40 \%$ of patients with stable moderate and severe COPD disease [7-10], and a higher proportion of patients studied at the time of an exacerbation [7]. Moreover, short-term treatment with oral corticosteroids does seem to be associated with significant benefits in patients with exacerbations of COPD [11]. Early, uncontrolled studies with long-term, low-dose prednisolone have suggested substantial treatmentassociated reductions in exacerbation frequency and rate of decline in FEV1 $[12,13]$.

These findings raise the possibility that COPD is an inhaled corticosteroid-resistant, oral corticosteroid-responsive condition. Two recent studies provide direct support for this view. Both studies were placebo-controlled crossover trials involving $\sim 60$ patients with moderate and severe COPD. The first study investigated 2 weeks of prednisolone $30 \mathrm{mg} \cdot \mathrm{day}^{-1}$ [8] and the other inhaled mometasone $400 \mu \mathrm{g}$ daily for 6 weeks [9]. Both studies showed that the treatment-associated improvement in FEV1 and quality of life scores increased progressively from the lowest to highest tertile of baseline sputum eosinophil count, consistent with a close, and perhaps causal, association between eosinophilic airway inflammation and the response to corticosteroids. However, the beneficial effects of oral prednisolone were substantially greater than those of inhaled mometasone. This was particularly the case with the sputum eosinophil count, which was reduced six-fold by prednisolone, but was unaffected by mometasone. Another recent study has shown that a management approach with the additional aim of reducing the sputum eosinophil count below $3 \%$ is associated with a $62 \%$ reduction in severe exacerbations of COPD requiring hospitalisation, when compared to traditional symptom-based management [14]. Anecdotally, we found in this study that it was often necessary to use oral prednisolone to achieve significant reductions in the sputum eosinophil counts in the intervention group.

A potential mechanism for the different effects of inhaled and oral corticosteroid resistance in COPD is that functionally important corticosteroid-responsive eosinophilic airway inflammation is confined to the distal lung, a site that is accessed by oral, but not inhaled, corticosteroids. Interestingly, studies in severe asthma show that oral, but not inhaled, corticosteroids reduce alveolar nitric oxide, strongly suggesting that this marker of distal lung inflammation reflects inflammation in a site that is differentially accessed by systemic and inhaled corticosteroids [15].

Other explanations consider a more absolute corticosteroid resistance in COPD, suggesting smoking and oxidative stress impair the ability of corticosteroids to recruit histone deactylase-2, which leads to transcription of pro-inflammatory genes [16]. This is not consistent with the observed difference in the clinical and anti-inflammatory efficacy of oral and inhaled corticosteroids.
If COPD is associated with an inhaled corticosteroid-resistant but oral corticosteroid-responsive functionally important distal eosinophilic airway inflammatory response, it follows that long-term treatment with oral corticosteroids might be associated with improvements in meaningful longer-term outcomes in patients with COPD, such as exacerbation frequency and decline in lung function, particularly when there is evidence of eosinophilic airway inflammation. Of course, long-term therapy with oral corticosteroids has a high potential for adverse effects in an elderly frail population, although the risk benefit may be acceptable if the maintenance dose is low and if care is taken to monitor and prevent osteoporosis, especially in the context of patients with severe disease suffering an expected 5-yr survival of $24-30 \%$ [17]. There is also the potential that effective anti-inflammatory therapy will be associated with a reduction in markers of systemic inflammation and reduced morbidity and mortality from associated conditions, such as coronary heart disease [18].

In a sense, experience with oral corticosteroid treatment in COPD parallels, but lags behind, experience with oral corticosteroid treatment in rheumatoid arthritis where opinion has swung from extreme enthusiasm to therapeutic nihilism and back to a view where they are helpful when used in low doses in selected patients [19].

We believe that the respiratory community will ultimately come to a similar conclusion. The time has come to investigate the effects and cost-effectiveness of long-term low-dose oral corticosteroid therapy in patients with chronic obstructive pulmonary disease who have evidence of eosinophilic airway inflammation.

\section{S. Saha, R. Siva, C.E. Brightling and I.D. Pavord}

Institute for Lung Health, Dept of Respiratory Medicine and Thoracic Surgery, Glenfield Hospital, Leicester, UK.

\section{REFERENCES}

1 Burge PS, Calverley PM, Jones PW, Spencer S, Anderson JA, Maslen TK. Randomised, double blind, placebo controlled study of fluticasone propionate in patients with moderate to severe chronic obstructive pulmonary disease: the ISOLDE trial. BMJ 2000; 320: 1297-1303.

2 The Lung Health Study Research Group. Effect of inhaled triamcinolone on the decline in pulmonary function in chronic obstructive pulmonary disease: Lung Health Study II. N Engl J Med 2000; 343: 1902-1909.

3 Vestbo J, Sorensen T, Lange P, Brix A, Torre P, Viskum K. Long-term effect of inhaled budesonide in mild and moderate chronic obstructive pulmonary disease: a randomised controlled trial. Lancet 1999; 353: 1819-1823.

4 Jones PW, Willits LR, Burge PS, Calverley PM. Disease severity and the effect of fluticasone propionate on chronic obstructive pulmonary disease exacerbations. Eur Respir J 2003; 21: 68-73.

5 Burge PS, Calverley PMA, Jones PW, Spencer S, Anderson JA. Prednisolone response in patients with chronic obstructive pulmonary disease: results from the ISOLDE study. Thorax 2003; 58: 654-658. 
6 Pavord ID, Siva R, Brightling CE. Prednisolone response in patients with COPD. Thorax 2004; 59: 179.

7 Saetta M, Di Stefano A, Maestrelli P, et al. Airway eosinophilia in chronic bronchitis during exacerbations. Am J Respir Crit Care Med 1994; 150: 1646-1652.

8 Brightling CE, Monteiro W, Ward R, et al. Sputum eosinophilia and short-term response to prednisolone in chronic obstructive pulmonary disease: a randomised controlled trial. Lancet 2000; 356: 1480-1485.

9 Brightling CE, McKenna S, Hargadon B, et al. Sputum eosinophilia and the short term response to inhaled mometasone in chronic obstructive pulmonary disease. Thorax 2005; 60: 193-198.

10 Confalonieri M, Mainardi E, Della Porta R, et al. Inhaled corticosteroids reduce neutrophilic bronchial inflammation in patients with chronic obstructive pulmonary disease. Thorax 1998; 53: 583-585.

11 Wood-Baker RR, Gibson PG, Hannay M, Walters EH, Walters JA. Systemic corticosteroids for acute exacerbations of chronic obstructive pulmonary disease. Cochrane Database Syst Rev 2005; 1: CD001288.

12 Postma DS, Peters I, Steenhuis E, Sluiter H. Moderately severe chronic airflow obstruction. Can corticosteroids slow down obstruction? Eur Respir J 1988; 1: 22-26.

13 Postma DS, Steenhuis EJ, van der Weele LT, Sluiter HJ. Severe chronic airflow obstruction: can corticosteroids slow down progression? Eur J Respir Dis 1985; 67: 56-64.
14 Siva $\mathrm{R}$, Green R, Brightling CE, et al. Modulation of eosinophilic inflammation in COPD. Eur Respir J 2005; 26: Suppl. 49, 441s.

15 Berry M, Hargadon B, Morgan A, et al. Alveolar nitric oxide in adults with asthma: evidence of distal lung inflammation in refractory asthma. Eur Respir J 2005; 26: 986-991.

16 Barnes PJ, Ito K, Adcock IM. Corticosteroid resistance in chronic obstructive pulmonary disease: inactivation of histone deacetylase. Lancet 2004; 363: 731-733.

17 National Collaborating Centre for Chronic Condintions. Chronic Obstructive Pulmonary Disease. National clinical guideline on management of chronic obstructive pulmonary disease in adults in primary and secondary care. Thorax 2004; 59: Suppl. 1, 1-232.

18 Sin DD, Lacy P, York E, Man SFP. Effects of fluticasone on systemic markers of inflammation in chronic obstructive pulmonary disease. Am J Respir Crit Care Med 2004; 170: 760-765.

19 van Everdingen AA, Jacobs JW, Siewertsz van Reesema DR, Bijlsma JW. Low-dose prednisone therapy for patients with early active rheumatoid arthritis: clinical efficacy, disease-modifying properties, and side effects: a randomized, double-blind, placebo-controlled clinical trial. Ann Intern Med 2002; 136: 1-12.

DOI: $10.1183 / 09031936.06 .00146705$

\section{The sulphoxidation of S-carboxymethyl-L-cysteine in COPD}

\section{To the Editors:}

Mucolytics, such as S-carboxymethyl-L-cysteine, have a role to play as an adjunct in the treatment of chronic obstructive airway disease, but their apparent unreliability has led to divided opinion concerning their usefulness [1-3]. The failure to achieve any measurable benefit with some patients presumably reflects underlying interindividual differences within the patient cohort, and not that the drug itself is without efficacy. In this respect, one major topic affecting clinical efficacy of a drug is its disposition and fate following administration, and, in particular, those factors that influence its subsequent metabolism and deactivation.

The metabolic fate of $S$-carboxymethyl-L-cysteine, an extensively used and widely available mucoactive drug, is now known to be complex. Detailed and rigorous studies in humans have revealed that the biotransformation of the drug varies widely within the same individual, with little sulphoxide (sulphur oxygenated) metabolites being produced following night-time administration [4]. This seemingly trivial observation is crucial, as recent work indicates that this drug functions as a free radical scavenger $[5,6]$ and that, in this respect, the sulphide (parent compound) is the active species with the sulphoxide metabolites (already oxidised) being inactive. Thus, a night-time intake of the drug should be more beneficial to the patient than daytime administration. However, this diurnal variation in metabolism (deactivation) is overlaid on an underlying genetic polymorphism that gives the patient population a spread of S-carboxymethyl-L-cysteine sulphoxidation capacities [7] (fig. 1). Those individuals who are relatively efficient sulphur oxidisers will rapidly produce inactive oxygenated metabolites, whereas those who have a relative deficiency in this process will be exposed to the active sulphide for a longer period of time, effectively mimicking the night-time dosing situation. In efficient sulphoxidisers, the standard dose of the drug may well have little effect. The underlying enzymology of these reactions is not yet clear, but two cytosolic enzymes, cysteine dioxygenase and phenylalanine 4-hydroxylase, have been implicated [8].

It is evident that a "broad brush stroke" approach to therapy with this particular mucolytic agent will not work for everyone. The recognition that the same dose of S-carboxymethyl-Lcysteine will not be equally effective for all patients should enable this part of the therapeutic regimen to be tailored to each individual patient, or subgroup, of patients. Removing or withholding treatment because it appears ineffective in some subjects is manifestly incorrect for that proportion of the 